\title{
ESTUDO CURRICULAR DE CURSOS SUPERIORES DE TECNOLOGIA E A MATEMÁTICA FINANCEIRA
}

\author{
H. Rosetti Júnior'; R. A. Santiago ${ }^{2}$ e J. Schimiguel ${ }^{3}$ \\ ${ }^{1}$ Instituto Federal do Espírito Santo (IFES), ${ }^{2,3}$ Universidade Cruzeiro do Sul (UNICSUL) \\ heliorosetti@terra.com.br ${ }^{1}$
}

Artigo submetido em setembro/2012 e aceito em março/2013

\section{RESUMO}

O presente trabalho tem por finalidade debater e refletir aspectos e características curriculares dos cursos superiores de tecnologia em uma instituição de ensino particular tecnológico no Estado do Espírito Santo. O estudo analisa, ainda, especificamente a presença de conhecimentos de Matemática Financeira e conteúdos de finanças nos currículos das graduações tecnológicas e suas influências na formação dos graduandos nessa modalidade de estudo superior. Para a análise e conclusões foram levadas em conta as diretrizes curriculares do MEC para os cursos superiores de tecnologia bem como as habilidades e competências definidas para essas graduações.

PALAVRAS-CHAVE: Currículo, Graduação Tecnológica, Matemática Financeira, Formação, Finanças.

\section{STUDY CURRICULUM COURSE OF HIGHER MATHEMATICS AND FINANCIAL TECHNOLOGY}

\section{ABSTRACT}

This study aims to discuss and reflect aspects of the curriculum and features courses in technology in a particular technological education institution in the state of Espirito Santo. The study also looks at the presence of specific knowledge of Financial Mathematics and Finance content in the curricula of graduate technology and its influence on the formation of the students in this type of higher education. For the analysis and conclusions were taken into account the Ministry of Education curriculum guidelines for undergraduate courses of technology and the skills and competencies defined for these grades.

KEY-WORDS: Curriculum, Graduate Technological, Financial Mathematics, Education, Finance. 


\section{ESTUDO CURRICULAR DE CURSOS SUPERIORES DE TECNOLOGIA E A MATEMÁTICA FINANCEIRA}

\section{INTRODUÇÃO}

O Currículo aparece pela primeira vez como objeto de estudo e pesquisa em 1920, nos Estados Unidos. O contexto é de expansão da industrialização e da urbanização, bem como da massificação da escola. Passa a ser necessária uma ferramente pedagógica que exerça a função de organização do ensino, pois a escola deve proporcionar a integração e adaptação das pessoas às transformações econômicas, sociais e culturais que ocorriam naquele contexto.

Explanar sobre currículo passa pela reflexão sobre o que precisamos ensinar na escola, a quem e em qual contexto histórico-político e social. O currículo é prática pedagógica com finalidades econômicas e sociais. Conforme Sacristán (2000) toda prática pedagógica gravita em torno do currículo, sendo assim,

\footnotetext{
... o estudo do currículo serve de centro de condensação e inter-relação de muitos outros conceitos e teorias pedagógicas, porque não existem muitos temas e problemas educativos que não tenham algo a ver com ele. (SACRISTÁN, 2000, p. 28)
}

O objeto de estudo deste artigo é o currículo de cursos de graduação tecnológicos. Sendo assim, os currículos podem ser distintos, terem funções e objetivos diferentes, e essas particularidades devem ser consideradas no estudo dos mesmos. As estruturas curriculares dos cursos de graduação tecnológica distinguem-se dos currículos dos demais cursos superiores pela objetividade e pelo foco no campo do saber. O entendimento dessas características nas graduações tecnológicas faz com que essa modalidade de curso tenha uma afinidade com o ambiente do trabalho, com vistas à inserção profissional.

Quanto ao currículo e sua concepção, merece ser ressaltado que:

Ao longo da história, o currículo reflete uma concepção de educação e de sua importância na sociedade, o que é muito diferente da importância acadêmica de cada disciplina (D'AMBROSIO, 2005).

Na perspectiva cultural do currículo, e acerca das questões implícitas que devem ser analisadas, vale destacar que:

O currículo é uma opção cultural, o projeto que quer tomar-se na cultura-conteúdo do sistema educativo para um nível escolar ou para uma escola de forma concreta. A análise desse projeto, sua representatividade, descobrir os valores que o orientam e as opções implícitas no mesmo, esclarecer o campo em que se desenvolve, condicionado por múltiplos tipos de práticas, etc. exige uma análise crítica que o pensamento pedagógico dominante tem evitado (SACRISTÁN, 2000, p.34).

Quanto aos valores presentes nos currículos e a respeito do exercício do poder na comunidade, deve-se ressaltar que:

É o compromisso com a manutenção de um sentido de comunidade, baseado na homogeneidade cultural e no consenso de valores, que foi e continua sendo um dos principais, embora tácitos, legados da área de currículo. (APPLE, 2006)

Os cursos de graduação tecnológica devem se estruturar, em termos curriculares, orientando-se, por um lado, para formar sólidas competências na medida do nível de ensino de 
graduação específica e, de outro, na perspectiva da educação permanente, preparando o futuro graduado para enfrentar os desafios das velozes transformações sociais, do mercado de trabalho e das condições do exercício profissional. Nesse sentido, conhecer os mecanismos básicos de finanças e suas análises a partir de modelos matemático-financeiros tem grande significado para a formação profissional.

Com isso, falar em currículo escolar ou acadêmico significa, sobretudo, falar também na vida do aluno e da comunidade escolar em permanente ação, isto é, educandos e educadores, no espaço escolar, constroem e formatam, através de processos de valorização e do cotidiano que vivenciam, o currículo apropriado para o desenvolvimento de competências e habilidades necessárias ao desenvolvimento educacional dos estudantes (ROSETTI; SCHIMIGUEL, 2009).

\begin{abstract}
O aluno que se confronta com os mais variados aspectos do currículo não é um Indivíduo abstrato, mas proveniente de um meio social concreto e com uma bagagem prévia muito particular que lhe proporciona certas oportunidades de alguma forma determinadas e um ambiente para dar significado ao currículo escolar (SACRISTÁN, 2000, p.61)
\end{abstract}

A busca de entendimento dos aspectos gerais da formação dos estudantes, não só para o mercado, mas também para a vida, exige que as propostas curriculares não se atenham a ajustes de forma, restritas a criação ou troca de disciplinas, de extensão do tempo escolar ou inclusão de atividades antes não previstas. Pensar em criar mecanismo de democratizar o acesso ao ensino superior e ações administrativas e pedagógicas que visem melhorar a qualidade do ensino é hoje o cerne da reflexão que demanda estruturações curriculares (ARRIEIRO, 2002)

Por outro lado, as mudanças realizadas no mundo do trabalho têm modificado as exigências para a entrada no mercado de trabalho, tornando cada vez mais urgentes as necessidades de jovens e adultos trabalhadores em melhorar e ampliar sua escolaridade e qualificar-se profissionalmente, o que procuram fazer, dentre outras formas, por meio de projetos ou programas estatais desenvolvidos em parceria com organizações da sociedade civil, como é o caso do Programa Nacional de Estímulo ao Primeiro Emprego (PNPE) (BARBOSA; DELUIZ, 2008).

Um dos saberes fundamentais à minha prática educativo-crítica é o que me adverte da necessária promoção da curiosidade espontânea para a curiosidade epistemológica. Outro saber indispensável à prática educativo-crítica é o de como lidaremos com a relação autoridade-liberdade, sempre tensa e que gera disciplina como indisciplina. (FREIRE, 2002)

Merece ser ressaltado o fato de que:

$\mathrm{Na}$ resolução de problemas, o tratamento de situações complexas e diversificadas oferece ao aluno a oportunidade de pensar por si mesmo, construir estratégias de resolução e argumentações, relacionar diferentes conhecimentos e, enfim, perseverar na busca da solução. E, para isso, os desafios devem ser reais e fazer sentido (BRASIL, 2002).

Vale ainda destacar que o desemprego e a desocupação dos jovens ${ }^{1}$ é um dos mais graves problemas da atualidade, pois a dramática situação da falta de postos de trabalho e as dificuldades de acesso à rede de proteção social transformam a fase da juventude em uma etapa de incerteza, carente de inclusão social e educacional (BARBOSA; DELUIZ, 2008).

\footnotetext{
${ }^{1}$ Segundo pesquisa do Ipea (Instituto de Pesquisa Econômica Aplicada) de 2008, o desemprego entre jovens de 15 a 24 anos é 3,5 vezes maior do que entre os trabalhadores considerados adultos, com mais de 24 anos.
} 
Os currículos dos cursos de tecnologia, por suas características, apresentaram nos últimos anos, uma grande possibilidade de adequação à nova realidade do ensino superior. Oferecidos num tempo mais objetivo que as graduações tradicionais, os cursos de tecnologia têm proporcionado grandes possibilidades de formação acadêmica, com baixo custo e elevada aderência às demandas das empresas. Isso permite com que essa modalidade de graduação tenha elevada procura e crescimento, nos últimos cinco anos (ROSETTI JUNIOR, 2006).

Há que se destacar, ainda, a busca em superar o atual distanciamento entre a teoria e prática, buscando qualificar os saberes da prática que, no decorrer da nossa história escolar, foram sendo desqualificados e silenciados enquanto parte da produção de conhecimento. A valorização dos saberes da prática, a reflexão sobre o que é conhecimento certo e o que a escola considera errado poderá contribuir significativamente para o acolhimento dos conhecimentos trazidos pelos alunos que freqüentam os cursos tecnológicos.

\section{CURRÍCULO E LEGISLAÇÃO}

Atualmente, pelas sofisticadas exigências tecnológicas, as empresas demandam dos profissionais competências refinadas e cada vez mais focadas em suas áreas de atuação. Observar nos cidadãos o domínio de áreas específicas do saber e a preocupação permanente por aprimoramentos e capacitação tem sido uma exigência unânime das organizações ao selecionar profissionais para suas equipes de trabalho. Os currículos dos cursos têm um grande papel na sintonia com o mundo do trabalho. (ROSETTI JUNIOR, 2010)

Os cursos superiores de tecnologia possuem orientação curricular própria definida a partir de decisão do Conselho Nacional de Educação, CNE, pela Resolução CNE/CP $n$ ㅇ 3, de $18 / 12 / 2002$, publicada no DOU em 23/12/2002. Essa orientação federal institui as Diretrizes Curriculares Nacionais Gerais para a organização e o funcionamento dos cursos superiores de tecnologia para todas as instituições de ensino superior. Essas orientações legais e curriculares estão reunidas no Catálogo Nacional de Cursos Superiores de Tecnologia ${ }^{2}$, para os diversos eixos de atuação e de saber.

\footnotetext{
O Catálogo organiza e orienta a oferta de Cursos Superiores de Tecnologia, inspirado nas Diretrizes Curriculares Nacionais para a Educação Profissional de Nível Tecnológico e em sintonia com a dinâmica do setor produtivo e os requerimentos da sociedade atual. Configurado, desta forma, na perspectiva de formar profissionais aptos a desenvolver, de forma plena e inovadora, as atividades em um determinado eixo tecnológico e com capacidade para utilizar, desenvolver ou adaptar tecnologias com a compreensão crítica das implicações daí decorrentes e das suas relações com o processo produtivo, o ser humano, o ambiente e a sociedade (BRASIL, 2010).
}

Nessa perspectiva, os cursos da faculdade pesquisada seguem essas orientações das diretrizes básicas na estruturação do currículo dos seus cursos.

\section{ANÁLISE DOS CURRÍCULOS}

Conforme os dados do Quadro 1, os cursos da área de Gestão e Negócios têm seus currículos reunindo tecnologias associadas aos instrumentos, técnicas e estratégias aplicadas na

\footnotetext{
${ }^{2}$ Lançado em junho de 2006, na época com 96 denominações, o Catálogo Nacional de Cursos Superiores de Tecnologia inaugurou rotinas dinâmicas de análise, inclusões e revisões de cursos nessa modalidade de graduação, podendo-se falar que o mesmo se constitui num espaço de discussões das possibilidades dos cursos de tecnologia.
} 
busca da qualidade, produtividade e competitividade das organizações. Engloba ações de planejamento, avaliação e gerenciamento de pessoas e processos referentes a negócios e serviços presentes em organizações públicas ou privadas, de todos os portes e segmentos de atuação. Esse eixo de conhecimento caracteriza-se pelas tecnologias organizacionais, viabilidade econômica, técnicas de comercialização, ferramentas de informática, estratégias de marketing, logística, finanças, relações interpessoais, legislação, normas e ética (BRASIL, 2010).

$\mathrm{Na}$ área de Gestão e Negócio encontram-se os cursos da faculdade em estudo de Comércio Exterior, Gestão Financeira, Marketing, Recursos Humanos e Logística.

$\mathrm{Na}$ área de Produção Industrial, conforme dados do Catálogo Nacional de Cursos Superiores de Tecnologia, os currículos compreendem tecnologias ligadas aos processos de transformação de matéria-prima, substâncias puras ou compostas, integrantes de linhas de produção específicas. Abrange planejamento, instalação, operação, controle e gestão dessas tecnologias no ambiente industrial. Devem contemplar programação e controle da produção, operação do processo, gestão da qualidade, controle de insumos, métodos e rotinas. Característica desse eixo é a associação de competências da produção industrial àquelas relacionadas ao objeto da produção na perspectiva da qualidade e da produtividade, da ética e do meio ambiente, viabilidade técnico-econômica, além do permanente aperfeiçoamento tecnológico (BRASIL, 2010).

Nesse grupo Produção Industrial faz parte o curso de tecnologia em Petróleo e Gás da faculdade de tecnologia.

As estruturas curriculares dos cursos pesquisados na instituição, seguindo as orientações básicas do MEC, apresentam as seguintes características:

- São constituídos em formato modular, por módulos semestrais com certificações intermediárias.

- Para os cursos na área de Gestão e Comércio, todos com um total de quatro módulos e duração mínima de dois anos, cada um desses módulos possui carga horária de quatrocentas horas semestrais.

- No curso de Petróleo e Gás, com um total de cinco módulos, cada um desses módulos possui quatrocentas e oitenta horas semestrais. O curso tem duração mínima de dois anos e meio.

- Os cursos têm suas cargas horárias totais dentro do mínimo estabelecido pelo MEC, conforme o Quadro 1.

- Possuem um módulo inicial comum básico gerencial, com as seguintes disciplinas: Comportamento Organizacional, Gestão Aplicada, Estatística, Métodos Quantitativos, Contabilidade e Comunicação Aplicada. Neste módulo são trabalhadas academicamente as competências gerenciais básicas para a formação profissional com vistas ao ingresso nas organizações e corporações.

- Para todos os cursos da faculdade na qual ocorreu a investigação, no módulo básico gerencial, nas disciplinas de Métodos Quantitativos, Contabilidade e Estatística, são trabalhadas competências, habilidades e bases tecnológicas voltadas para as áreas quantitativa e financeira do saber, com uma carga horária total de duzentas horas semestrais, o que representa metade de toda a carga horária do módulo para os cursos de Gestão e Comércio.

- Todos os cursos da área de Gestão e Comércio, por suas estruturas curriculares, permitem aos egressos formados o registro profissional no Conselho Regional de Administração (CRA). O curso de Petróleo e Gás, por sua composição curricular, permite aos alunos formados registro profissional no Conselho Regional de Química (CRQ). 
Percebe-se que, nos currículos das formações de tecnólogos em questão, além das disciplinas do módulo básico gerencial, outras disciplinas dos cursos envolvem cálculos financeiros, quais sejam:

- Comércio Exterior - Economia Empresarial, Economia Internacional, Custos Logísticos, Sistemática Cambial Brasileira.

- Recursos Humanos - Estrutura de Remuneração, Administração de Cargos Salários e Benefícios.

- Gestão Financeira - Economia Empresarial, Mercado Financeiro, Matemática Financeira, Análise Econômica e Financeira, Análise de Projetos de Investimentos, Finanças Internacionais, Mercado de Capitais, Finanças Corporativas, Orçamento e Controle Controladoria,

- Marketing - Formação e Administração de Preços, Finanças Corporativas.

- Logística - Economia Empresarial, Gestão Financeira e de Custos Logísticos, Logística Industrial e Globalização Econômica.

- Petróleo e Gás - Cálculo Aplicado, Cálculo Avançado, Análise Econômica de Projetos Petrolíferos, Engenharia de Poço, Engenharia de Produção.

Com isso, nota-se que além de uma formação matemática financeira básica, os alunos envolvidos no processo vivenciam, ao longo de seus cursos, aplicações matemáticas e estudos financeiros, propiciando uma compreensão mais aprimorada das questões financeiras do cotidiano.

Verifica-se, também, na instituição, conforme o Quadro 1, que as diretrizes do MEC para os cursos pesquisados, contemplam aspectos ligados à matemática financeira, facilitando o entendimento dos alunos nas operações sobre valores financeiros.

Portanto, é possível inferir, que os conteúdos curriculares atendem às exigências de uma sociedade de economia globalizada, apresentando conteúdos, no campo dos conhecimentos básicos, que abrangem a discussão de uma economia globalizada.

No que tange aos conhecimentos práticos, o currículo prevê uma formação com vivências e aplicação dos conhecimentos matemáticos e financeiros, com vistas a garantir a compreensão das questões financeiras do cotidiano.

Apresentam, assim, um currículo fundamentado em novas dimensões de uma sociedade globalizada, estabelecendo novas relações no processo e prática educacional. A educação continua a constituir um capital humano para uma nova ordem social.

Quadro 1 - Diretrizes curriculares do catálogo nacional de cursos superiores de tecnologia

\begin{tabular}{|c|l|c|}
\hline \multicolumn{2}{|c|}{ DIRETRIZES CURRICULARES DO CATÁLOGO NACIONAL DE CURSOS SUPERIORES DE TECNOLOGIA } \\
\hline CURSO & \multicolumn{1}{|c|}{ DIRETRIZES BÁSICAS } & $\begin{array}{c}\text { CARGA } \\
\text { HORÁRIA } \\
\text { MíNIMA }\end{array}$ \\
\hline $\begin{array}{c}\text { COMÉRCIO } \\
\text { EXTERIOR }\end{array}$ & $\begin{array}{l}\text { O Tecnólogo em Comércio Exterior gerencia operações de comércio } \\
\text { exterior, tais como: transações cambiais, despacho e legislação aduaneira, } \\
\text { exportação, importação, contratos e logística internacional. Prospecta e } \\
\text { pesquisa mercados, define planos de ação, negocia e executa operações } \\
\text { legais, tributárias e cambiais inerentes ao processo de exportação e } \\
\text { importação. Além disso, controla fluxos de embarque e desembarque de } \\
\text { produtos, providencia documentos e identifica os melhores meios de } \\
\text { transporte, de forma a otimizar os recursos financeiros e humanos para o } \\
\text { comércio exterior. }\end{array}$ \\
\hline
\end{tabular}




\begin{tabular}{|c|c|c|}
\hline $\begin{array}{l}\text { RECURSOS } \\
\text { HUMANOS }\end{array}$ & $\begin{array}{l}\text { O Tecnólogo em Gestão de Recursos Humanos atua no planejamento e } \\
\text { gerenciamento dos subsistemas de gestão de pessoas, tais como } \\
\text { recrutamento e seleção, cargos e salários, treinamento e desenvolvimento, } \\
\text { avaliação de desempenho, rotinas de pessoal, benefícios, gestão de } \\
\text { carreiras e sistema de informação de recursos humanos. Esse profissional } \\
\text { promove o desenvolvimento de competências relacionadas ao } \\
\text { comportamento nos níveis individual (motivação), de grupo (negociação, } \\
\text { liderança, poder e conflitos) e organizacional (cultura, estrutura e } \\
\text { tecnologias), catalisando os processos de elaboração de planejamento } \\
\text { estratégico, programas de qualidade de vida do trabalho e avaliação do } \\
\text { clima organizacional. }\end{array}$ & $1600 \mathrm{H}$ \\
\hline $\begin{array}{c}\text { GESTÃO } \\
\text { FINANCEIRA }\end{array}$ & $\begin{array}{l}\text { O Tecnólogo em Gestão Financeira aplica métodos, técnicas e conceitos } \\
\text { econômico-financeiros no planejamento de captação e investimento dos } \\
\text { recursos empresariais, na controladoria, trabalhando em diferentes } \\
\text { cenários e ambientes organizacionais de uma empresa. Atento às } \\
\text { mudanças econômicas e tecnológicas, e com vistas a otimizar } \\
\text { investimentos, esse profissional analisa demonstrações financeiras e } \\
\text { elabora estudos de viabilidade, subsidiando assim o processo de tomada } \\
\text { de decisões na instituição. }\end{array}$ & $1600 \mathrm{H}$ \\
\hline MARKETING & $\begin{array}{l}\text { O Tecnólogo em Marketing é o profissional responsável pela elaboração de } \\
\text { estratégias de vendas que atraiam e mantenham clientes. Ele estuda o } \\
\text { mercado e seu ambiente sócioeconômico para criar e inovar produtos ou } \\
\text { serviços, promovendo-os, solidificando sua marca no mercado e definindo } \\
\text { estratégias, público-alvo e preços a serem praticados. Atento às constantes } \\
\text { mudanças, esse profissional comunica e cria relacionamentos com } \\
\text { consumidores, antecipa tendências, aproveita oportunidades de mercado } \\
\text { e analisa riscos. Aspectos da legislação que regulam as atividades de } \\
\text { comercialização, consumo, contratos comerciais, normas de higiene e } \\
\text { segurança, questões tributárias e fiscais, estão diretamente ligados às } \\
\text { atribuições desse profissional. }\end{array}$ & $1600 \mathrm{H}$ \\
\hline LOGÍSTICA & $\begin{array}{l}\text { O Tecnólogo em Logística é o profissional especializado em armazenagem, } \\
\text { distribuição e transporte. Atuando na área logística de uma empresa, } \\
\text { planeja e coordena a movimentação física e de informações sobre as } \\
\text { operações multimodais de transporte, para proporcionar fluxo otimizado e } \\
\text { de qualidade para peças, matérias-primas e produtos. Ele gerencia redes } \\
\text { de distribuição e unidades logísticas, estabelecendo processos de compras, } \\
\text { identificando fornecedores, negociando e estabelecendo padrões de } \\
\text { recebimento, armazenamento, movimentação e embalagem de materiais, } \\
\text { podendo ainda ocupar-se do inventário de estoques, sistemas de } \\
\text { abastecimento, programação e monitoramento do fluxo de pedidos. }\end{array}$ & $1600 \mathrm{H}$ \\
\hline $\begin{array}{l}\text { PETRÓLEO E } \\
\text { GÁS }\end{array}$ & $\begin{array}{l}\text { O Tecnólogo em Petróleo e Gás gerencia, monitora e executa a } \\
\text { prospecção, extração, beneficiamento ou produção, armazenagem e } \\
\text { comercialização do petróleo e seus derivados. Em sua atuação, esse } \\
\text { profissional aplica a legislação do setor, afere a qualidade do produto, bem } \\
\text { como gerencia situações de emergência, com vistas ao controle de } \\
\text { acidentes de trabalho e ambientais. O curso deve enfatizar, considerando a } \\
\text { vocação regional, uma ou mais etapas do processo produtivo do petróleo e } \\
\text { gás, dessa forma, esse tecnólogo pode atuar em jazidas, plataformas, } \\
\text { refinarias e distribuidoras, conforme sua formação. }\end{array}$ & $2400 \mathrm{H}$ \\
\hline
\end{tabular}

Fonte: MEC 
Visando reunir as informações essenciais dos currículos dos cursos da faculdade analisada nesta pesquisa, no Quadro 2 organizou-se os objetivos dos currículos, juntamente com o perfil profissional de cada curso, com vistas a uma comparação das competências a serem implementadas nos vários módulos curriculares. Esses objetivos e perfis profissionais são definidos pela instituição, em seus projetos pedagógicos e no plano de desenvolvimento institucional, em consonância com as demandas do mercado local e em observância às orientações do MEC e dos conselhos profissionais.

Nota-se que cada curso tem um foco curricular bem definido, com objetivos bem demarcados, visando preparar com profundidade o profissional que atuará nas áreas do saber escolhidas, em atendimento às definições estabelecidas pelo MEC.

Quadro 2 - Comparação dos objetivos curriculares dos cursos superiores de tecnologia pesquisados

\begin{tabular}{|c|l|}
\hline \multicolumn{2}{|c|}{ COMPARAÇÃO DOS OBJETIVOS CURRICULARES DOS CURSOS SUPERIORES DE TECNOLOGIA } \\
PESQUISADOS
\end{tabular}




\begin{tabular}{|c|c|}
\hline $\begin{array}{c}\text { GESTÃO } \\
\text { FINANCEIRA }\end{array}$ & $\begin{array}{l}\text { Objetivos } \\
\text { O Curso Superior de Tecnologia em Gestão Financeira tem o objetivo de formar } \\
\text { especialistas qualificados para desenvolverem os investimentos e conseguir mais } \\
\text { lucros, além de avaliar todos os impactos por meio de análise de custos. O gestor } \\
\text { financeiro aprenderá a analisar o crédito por meio de controles e registros gerenciais } \\
\text { e também realizará planilhas relativas ao mercado de ações e capitais. } \\
\text { Perfil Profissional } \\
\text { Qualificação holística nas áreas de finanças e controladoria, com foco nos conceitos } \\
\text { financeiros sob o ponto de vista analítico e prático, considerando o cenário } \\
\text { econômico-financeiro nacional e internacional. Para tanto se utilizarão conceitos e } \\
\text { técnicas que permitam realizar, na prática, o planejamento em empresas, com o } \\
\text { objetivo na avaliação de riscos e a seleção entre várias estratégias disponíveis. } \\
\text { Conceber ainda uma formação homogênea e um conhecimento mais específico na } \\
\text { área de Finanças, com destaque a gestão do fluxo de caixa, capital de giro, mercado } \\
\text { financeiro (bolsa de valores), câmbio, modelagem de empresas, controladoria e } \\
\text { avaliação de negócios / empresas para efeito de planejamento financeiro e de direção } \\
\text { executiva de toda a área financeira. }\end{array}$ \\
\hline MARKETING & $\begin{array}{l}\text { Objetivos } \\
\text { O Curso Superior de Tecnologia em Marketing tem por objetivo formar tecnólogos } \\
\text { com capacidade de analisar, planejar, implementar e avaliar as ações gerenciais } \\
\text { mercadológicas nas empresas, construir estratégias de marketing, coordenar } \\
\text { campanhas de divulgação, posicionamento e gerenciamento de marca. } \\
\text { Perfil Profissional } \\
\text { Formação para avaliar o potencial da demanda visando o equilíbrio da oferta no } \\
\text { mercado. Entender o comportamento do consumidor. Entender o processo decisorial } \\
\text { e comportamental de indivíduos, grupos e organizações no mercado consumidor. } \\
\text { Conhecer e aplicar os recursos de informática relativos ao marketing. } \\
\text { Conhecimento e aplicação das principais técnicas de vendas. Planejar objetivos, metas } \\
\text { e estratégias de vendas. Desenvolver treinamento, ações motivacionais e supervisão } \\
\text { de vendedores. } \\
\text { Planejar o desenvolvimento de produtos, marcas e embalagens. Analisar os sistemas } \\
\text { vertical, horizontal e híbrido de distribuição. Elaborar planilhas de custos relacionadas } \\
\text { ao marketing. } \\
\text { Conhecimento e aplicação das técnicas de planejamento estratégico, tático e } \\
\text { operacional no ambiente de marketing. Saber gerenciar o tempo como um elemento } \\
\text { estratégico em marketing. Criar e desenvolver estratégias mercadológicas mais } \\
\text { adequadas para atuação no mercado. }\end{array}$ \\
\hline LOGÍSTICA & $\begin{array}{l}\text { Objetivos } \\
\text { O Curso Superior de Tecnologia em Logística tem por objetivo formar tecnólogo } \\
\text { especializado nestas áreas: armazenagem, distribuição e transporte. Esse profissional } \\
\text { planeja, coordena e cuida da movimentação física e das informações sobre as } \\
\text { operações de transporte. Também gerencia redes de distribuição e unidades } \\
\text { logísticas, estabelece processos de compras, identifica fornecedores, além de realizar } \\
\text { o monitoramento do fluxo de pedidos. Expedição e gerenciamento de rota. } \\
\text { Perfil Profissional } \\
\text { Analisar custos logísticos relacionados ao deslocamento de mercadorias pertinentes à } \\
\text { competitividade no mercado nacional e internacional. Coordenar o armazenamento e } \\
\text { movimentação de materiais e os tipos de embalagens utilizados. Classificar a } \\
\text { geopolítica de transportes e custo energético nos diferentes modais, além de avaliar }\end{array}$ \\
\hline
\end{tabular}




\begin{tabular}{|c|c|}
\hline & os impactos da globalização nas demandas logísticas. \\
\hline $\begin{array}{c}\text { PETRÓLEO E } \\
\text { GÁS }\end{array}$ & $\begin{array}{l}\text { Objetivos } \\
\text { O profissional formado pela Faculdade no Curso Superior de Tecnologia em Petróleo e } \\
\text { Gás está preparado para atuar em diferentes segmentos como: gerenciar, monitorar e } \\
\text { executar a prospeç̧ão, extração, beneficiamento ou produção, armazenagem e } \\
\text { comercialização do petróleo e seus derivados, além de aplicar a legislação do setor e } \\
\text { gerenciar situações de emergência, com vistas ao controle de acidentes de trabalho } \\
\text { ambientais. } \\
\text { Perfil Profissional } \\
\text { Prestar assessoria nos segmentos relacionados em toda a cadeia produtiva do } \\
\text { petróleo, como: exploração e produção (upstream) nos processos relacionados com a } \\
\text { descoberta de petróleo; refino e comercialização (downstream) no beneficiamento do } \\
\text { petróleo e gás; logística e transporte (midstream) na gestão dos custos logísticos } \\
\text { relacionados ao deslocamento de mercadorias pertinentes à competitividade nos } \\
\text { mercados nacional e internacional. Coordenar o armazenamento e movimentação de } \\
\text { materiais e os tipos de embalagens utilizados e assessorar os especialistas a classificar } \\
\text { os fatores geopolíticos de transportes e custo energético nos diferentes modais para o } \\
\text { petróleo. Avaliar os impactos da globalização nas demandas logísticas e coordenar } \\
\text { equipes de marketing e vendas dos derivados de petróleo. }\end{array}$ \\
\hline
\end{tabular}

Fonte: Faculdade de Tecnologia Faesa ${ }^{3}$

Conforme o Quadro 2, percebe-se que nos objetivos curriculares dos cursos são trabalhadas academicamente competências e habilidades que exigem conhecimentos de matemática financeira e de finanças. Assim, saber lidar com gerenciamento de processos, gerenciamento de custos, efetuar compras e vendas, identificar tendências de mercados, classificar e posicionar carteiras de investimentos, analisar planos de carreira e remuneração, otimizar processos, avaliar ativos, entre várias competências, são objetivos dos cursos contidos em seus currículos.

Percebe-se, ainda, que existe uma forte relação entre as diretrizes curriculares do Catálogo Nacional de Cursos Superiores de Tecnologia, do Quadro 1, e os objetivos e também o perfil profissional dos cursos, no Quadro 2, demonstrando uma preocupação da instituição em seguir as orientações curriculares emanadas do MEC. Cabe destacar que os currículos pesquisados vão além das diretrizes, tendo em vista as demandas regionais específicas e as características dos cursos e da instituição.

Enfim, tanto a formação geral, módulo básico gerencial, e a formação prática apresentam elementos que demonstram que o currículo nos cursos superiores de tecnologia apresentam conteúdos específicos que

correspondem a complexos tecnológicos que envolvem aspectos da realidade natural e social implicados na atividade humana do trabalho, transpostos para outro contexto de trabalho, o educacional, alicerçados em sólidas bases científicas e nas especificidades dos saberes profissionais.(MACHADO, 2008, p. 21)

${ }^{3}$ Do endereço: http://www.cetfaesa.com.br/cetfaesa/site/institucional/Default.aspx>. Acesso em: 10 de jun. 2010. 


\section{CONSIDERAÇÕES FINAIS}

Por meio deste artigo, buscamos apresentar o debate acerca das características curriculares dos cursos superiores de tecnologia em uma instituição de ensino particular tecnológico no Estado do Espírito Santo. Nesse sentido, apresentamos as diretrizes teóricas e práticas dos cursos expondo e analisando como se processa a formação geral, no módulo básico gerencial, e a formação prática, que integra a vivência e a aplicação dos conhecimentos matemáticos e financeiros, ressaltando a sua finalidade em realizar a relação teoria e prática na medida que as questões financeiras estão relacionadas ao cotidiano do mundo do trabalho.

O estudo analisou, ainda, especificamente a presença de conhecimentos de Matemática Financeira e conteúdos de finanças nos currículos das graduações tecnológicas e suas influências na formação dos graduandos nessa modalidade de estudo superior. Observamos, assim, que a globalização da economia tem sido considerada no processo de formação dos estudantes procurando superar o desafio do sistema educacional em preparar os sujeitos para as necessidades da sociedade no contexto atual.

Um outro aspecto a ser considerado nos objetivos e no perfil profissional constantes nos currículos pesquisados é o fato dos cursos tecnológicos participarem do Exame Nacional de Desempenho de Estudantes (Enade) ${ }^{4}$, que integra o Sistema Nacional de Avaliação da Educação Superior (Sinaes), e que tem por objetivo aferir o rendimento dos alunos dos cursos de graduação em relação aos conteúdos programáticos, suas habilidades e competências. Os conteúdos exigidos no Enade passam a integrar os currículos dos cursos pelo fato de os alunos serem avaliados com base nessas habilidades e competências exigidas no exame nacional.

Dessa maneira, saber operar com valores financeiros, entender o significado desses valores no presente e no futuro, conhecer os montantes financeiros reunidos num valor ou parcelados, converter essas quantias em bases monetárias, entre várias outras habilidades, mostram-se essenciais na atuação profissional dos formandos dos cursos superiores de tecnologia pesquisados, num mundo do trabalho exigente e rico em informações financeiras. (ROSETTI JUNIOR, 2010).

Cabe ressaltar que os cursos tecnológicos da faculdade seguem uma estrutura curricular definida essencialmente pelo MEC. Entretanto, observou-se que, nos currículos, o tema matemática financeira não aparece como uma disciplina nos módulos básicos, sendo trabalhada dentro da disciplina de Métodos Quantitativos como mais um conteúdo no rol de outros conhecimentos matemáticos.

\section{REFERÊNCIAS:}

APPLE, Michael W. Ideologia e Currículo. São Paulo: Artmed, 2006.

ARRIEIRO, Daniel Henrique Lucci. Estágio e currículo: função pedagógica e função social Estudo de caso do Estágio Supervisionado no curso de Bacharelado em Administração da Faculdade de Ciências Administrativas de Curvelo. Dissertação (Mestrado em Educação)Programa de Pós-Graduação em Educação, Universidade Católica de Minas Gerais, Belo Horizonte, 2002.

\footnotetext{
${ }^{4} 2009$ foi o primeiro ano de participação no ENADE dos cursos superiores de tecnologia em Gestão.
} 
BARBOSA, Carlos Soares ; DELUIZ, Neise. Qualificação profissional de jovens e adultos trabalhadores : primeiro emprego em discussão. Boletim Técnico do Senac, Rio de Janeiro, v. 34, n. 1, p. 50-63, jan./abr. 2008.

BRASIL, Ministério da Educação. Catálogo Nacional de Cursos Superiores de Tecnologia. Disponível em:< http://catalogo.mec.gov.br/ >. Acesso em 09 jun.2010.

BRASIL, Ministério da Educação. PCN+. Brasília: Ministério da Educação, 2002.

D’AMBROSIO, Ubiratan. Sociedade, cultura, matemática e seu ensino. Educação e Pesquisa, São Paulo, v. 31, n. 1, p. 99-120, jan./abr. 2005. Disponível em: <http://www.scielo.br/pdf/ep/v31n1/a08v31n1.pdf>. Acesso em: 06 dez. 2009.

FREIRE, Paulo. Pedagogia da autonomia: saberes necessários à prática educativa. São Paulo: Paz e Terra, 1996.

MACHADO, Lucília R. de S. Diferenciais inovadores na formação de professores para a educação profissional. Revista Brasileira da Educação Profissional e Tecnológica. Brasília, MEC/SETEC, 2008. p. 8-22. http://portal.mec.gov.br/setec/arquivos/pdf3/rev_brasileira.pdf Acesso em: 29 out. 2011.

ROSETTI JUNIOR, Helio . Educação Matemática e Financeira: um estudo de caso em Cursos Superiores de Tecnologia. São Paulo: Universidade Cruzeiro do Sul, 2010. (Tese de Doutorado).

ROSETTI JUNIOR, H.; SCHIMIGUEL, J.. Educação matemática financeira: conhecimentos financeiros para a cidadania e inclusão. InterScience Place, v. 2, p. 1-13, 2009.

ROSETTI JUNIOR, Helio. Graduação e Inovação. Disponível em: http://www.administradores.com.br/informe-se/artigos/graduacao-e-inovacao/11829/ , Acesso em: 09 jun. 2006.

SACRISTÁN, J. Gimeno. O currículo: uma reflexão sobre a prática. Porto Alegre: Artmed, 2000. 